\title{
Transposons and integrons: Natural genetic engineering of bacterial resistance
}

\author{
Paul H Roy PhD
}

\begin{abstract}
Transposons and integrons: Natural genetic engineering of bacterial resistance. Can J Infect Dis 1999;10(Suppl C):4C-8C.

The advent of antibiotics in clinical medicine has resulted in the emergence of multiresistant strains of bacteria. Bacteria possess sophisticated mechanisms of genetic exchange that have driven their recent evolution. Among these are transposons and integrons, the latter having interesting parallels with genetic engineering techniques used in the laboratory. An understanding of these mechanisms through studies of the molecular basis of the dissemination of resistance genes will aid rational choices in antibiotic therapy.
\end{abstract}

Key Words: Antibiotic; Expression vector; Integron; Resistance; Transposon

\begin{abstract}
Transposons et intégrons : génie génétique naturel de la résistance bactérienne
RÉSUMÉ : L'avènement des antibiotiques en médecine clinique a entraîné l'émergence de souches de bactéries multirésistantes. Les bactéries sont dotées de mécanismes complexes d'échange génétique qui ont favorisé leur évolution récente. Parmi ceux-là sont les transposons et les intégrons, les derniers pouvant, de façon intéressante, se comparer sur certains aspects aux techniques de génie génétique utilisées en laboratoire. La compréhension de ces mécanismes par le biais d'études sur les bases moléculaires de la dissémination des gènes de la résistance permettra de faire des choix raisonnables pour l'antibiothérapie.
\end{abstract}

$\mathrm{S}$ ince the advent of sulpha drugs and penicillin, antibiotics have been considered 'miracle drugs', that were expected to put an end to infectious diseases of bacterial origin. We now speak of the 'end of the miracle' or of an 'apocalypse' as a ' $r$ eturn to the preantibiotic era' looms on the horizon due to the emergence of multiresistant strains of bacteria (1-3). The human and veterinary use of antibiotics (including their use as animal growth promoters) have provided an intensive selection pressure on bacteria. The ability of bacteria to adapt, by mutation and selection, signalling and gene regulation, and by gene rearrangement and genetic exchange, has resulted in their acquisition and expression of a variety of resistance genes that have not previously been known to occur in common pathogens. These genes have been evolving for millions of years in bacteria, and fungi-producing antibiotics and those cohabiting with them in the environment but have only recently become associated with genetic elements that permit bacteria to share these genes, rearrange them and retain the successful combinations.

\section{RESISTANCE GENES}

Enzymatic resistance is among the most common of resistance mechanisms. The most well known example is that of beta-lactamases, the first of which was discovered shortly af- 


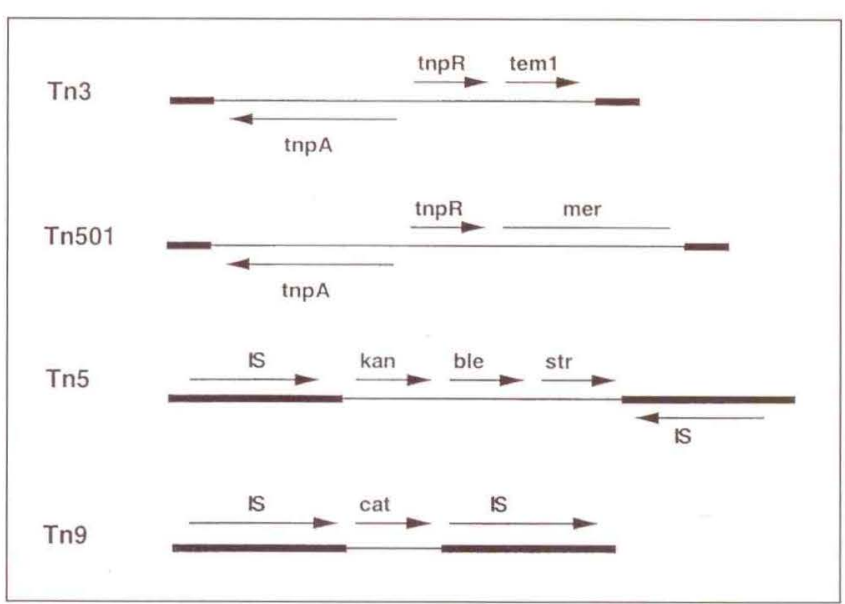

Figure 1) Representative simple ( $\operatorname{Tn} 3$ and $\operatorname{Tn} 501)$ and complex (Tn5 and Tn9) transposons. Simple transposons of the Tn3 family are flanked by short, inverted repeats; their transposase (tnpA) and resolvase (tnpR) genes are in the central segment. Complex transposons are flanked by insertion sequences (IS), which code for transposition functions, in either inverted or direct repeats. ble Bleomycin resistance; cat Chloramphenicol acetyltransferase; kan Kanamycin resistance; mer Mercury resistance; str Streptomycin resistance; tem 1 Tem-1 beta-lactamase

ter the discovery of penicillin. The synthesis of semisynthetic, beta-lactamase-resistant penicillins and beta-lactamase inhibitors appeared to solve this problem; however, recently, extended spectrum beta-lactamases have become widespread, at least in certain countries (4). There are three major types of these enzymes: point mutants of the TEM and SHV betalactamases, the appearance on plasmids of class A betalactamases such as CTX-M-2 and PER-2, which already have an extended spectrum profile, and derepression of the chromosomal class $\mathrm{C}$ ampc beta-lactamase or its transfer to plasmids without the accompanying repressor gene.

Aminoglycoside resistance is mediated by a variety of acetyltransferases, adenylyltransferases and phosphotransferases. Among the first examples were AAD- $\left(3^{\prime \prime}\right)$, coded by one of the earliest integron-mediated resistances, which mediates resistance to streptomycin and spectinomycin, and $\mathrm{APH}-\left(3^{\prime}\right)$, coded by $T n 5$, which mediates resistance to kanamycin. The development of newer aminoglycosides such as tobramycin, netilmicin and gentamicin have provided compounds that are insensitive to these mechanisms, but a host of newer genes, in particular the aminoglycoside acetyltransferases coded by integrons, have severely limited their clinical usefulness (5). More recently, synthetic aminoglycosides such as amikacin have been widely used, but, once again, new resistance genes have appeared. One of these genes, aacA4, mediates resistance to amikacin and appears to have resulted from a point mutation of a gentamicin resistance gene (6).

Chloramphenicol acetyltransferase, such as that mediated by $T n 9$, is a well studied resistance mechanism. Over a dozen genes, all of the same family, have been sequenced, and some of the enzymes have been crystallized and their structure de- termined. More recently, a completely different family of chloramphenicol acetyltransferases has been found that have no sequence homology with the main family (7-9). The discovery of these enzymes led to the discovery of similar enzymes encoded by Gram-positive bacteria such as enterococci and staphylococci $(10,11)$, which acetylate substrates, such as streptogramin A and virginiamycin, and may compromise the usefulness of these 'last-resort' antibiotics for problem bacteria such as vancomycin-resistant enterococci (VRE), methicillin-resistant Staphylococcus aureus (MRSA) and eventually vancomycin-resistant staphylococci.

Another common type of resistance mechanism is altered targets or bypass mechanisms. The best known of the former are the penicillin-binding proteins; either a completely new penicillin-binding protein (PBP) insensitive to beta-lactam antibiotics, as in MRSA, or resistance acquired by accumulation of point mutations in existing PBPs, as in penicillin-resistant pneumococci $(12,13)$. The best known of the bypass mechanisms are sulphonamide-resistant dihydropteroate synthase, usually coded by integrons and a variety of trimethoprimresistant dihydrofolate reductases, also integron coded (14).

Bacteria also produce transmembrane proteins that act as molecular pumps. Some of these are specific (eg, the tetracycline efflux protein coded by $\mathrm{Tn} 1 \mathrm{O}$ and the chloramphenicol efflux protein CmlA coded by integrons, while others are less specific, usually chromosomally encoded, multiple drug efflux proteins such as EmrD of Escherichia coli and the MexAB system of Pseudomonas aeruginosa $(15,16)$. These proteins are all members of a larger family of proteins, the 'major facilitator family', which includes sugar transporters, etc, from which the antibiotic transporters may have evolved (17).

\section{SIMPLE TRANSPOSONS}

Among the best known simple transposons is Tn3 (Figure 1), which carries the gene for the TEM beta-lactamase, which is widespread among Gram-negative bacteria. It also contains two genes for transposition functions, and is closely related to Tn1000 (gamma-delta), which contains only the latter two genes and, thus, has no phenotype other than its own transfer. Tn 3 at some point acquired (by an unknown mechanism) a class A beta-lactamase gene (from an unknown source), becoming an efficient vehicle for moving the betalactamase gene from chromosome to plasmid, from one plasmid to another and, thanks to conjugative plasmids, from one species to another. Since its arrival in enteric bacilli and spreading of resistance to penicillins (first noted in Japan in the late 1950s), $\operatorname{Tn} 3$ has been responsible for two other phenomena: the emergence of resistance to third-generation cephalosporins, largely due to the selection of a variety of point mutations in the TEM beta-lactamase gene, which alters the accessibility of the enzyme's active site to a new variety of substrates; and the transfer of Tn3 to Haemophilus and Neisseria species in the early 1970 s. The latter event resulted in the transfer, probably by conjugation but possibly by transformation, of plasmid DNA containing Tn3 to Haemophilus ducreyi, where this DNA was unable to replicate, but where Tn 3 then 'hopped' to a native plasmid. The $H$ ducreyi plasmids are 
the 'smoking gun' because they contain all of Tn3. A streamlined version, having lost the transposase gene (no longer necessary because the plasmids are spread out among haemophilus and neisseria by transformation) is found not only in $H$ ducreyi but also in Haemophila parainfluenzae and Neisseria gonorrhoeae, where it caused the emergence of the well known penicillinase-producing $N$ gonorrhoeae (PPNG) (18). Surprisingly, the TEM gene has not evolved in these organisms despite the widespread use of ceftriaxone to treat PPNG - does $N$ gonorrhoeae have a very faithful DNA polymerase?

Antibiotic resistance genes are by no means the only ones to be acquired by transposons; other genes include heavy metal resistance (eg, mercury resistance in Tn501) and even the lactose operon (enabling normally lac- bacteria to use an additional source of carbon), but also enabling pathogenic enteric bacilli to fool unwary bacteriologists accustomed to ignoring lactose-positive strains.

Another simple transposon, a member of the Tn3 family but found in enterococci, is Tn1546. In addition to the transposase and resolvase genes, this transposon contains an operon (a group of genes expressed as a unit from a single mRNA molecule) involved in the systhesis of an alternative pentapeptide, resistant to vancomycin, in its cell wall. Moreover, this operon is under the control of a two-component signalling system, vanRS, resulting in expression of the operon only when vancomycin is present in the medium (19). This enables the alternative (and presumably weaker) cell wall to be synthesized only in the presence of glycopeptides. The fortuitous association between vanRS and the resistance operon is demonstrated by the recent description of the vancomycin resistance operon - without vanRS because the gene expression is constitutive - in producing organisms (20).

\section{COMPLEX TRANSPOSONS}

Complex transposons are made up of two identical (or almost identical) insertion sequences, in direct or inverted repeat orientation, flanking a central region (Figure 1). Examples are Tn9, which carries the gene for the most common sort of chloramphenicol acetyltransferase, and Tn10, which carries a gene encoding a specific efflux pump for tetracycline resistance. The insertion sequences carry the gene(s) necessary for transposition. Another common complex transposon is Tn5, whose central region carries three resistance genes, including the aminoglycoside phosphotransferase mediating kanamycin resistance. Because the entire complex transposon moves as a unit and the genes of only one of the insertion sequences are necessary for mobility, Tn5 has undergone an interesting adaptation; a single point mutation in one of the insertion sequences stops the translation of the transposition proteins, but creates at the same time a promoter for expression of the resistance genes in the central seg ment.

It is easier to see how complex transposons formed in the first place. In all probability, they are due to the arrival of insertion sequences, first on one side and then on the other, of a resistance gene or operon. A recent example pointing to such a

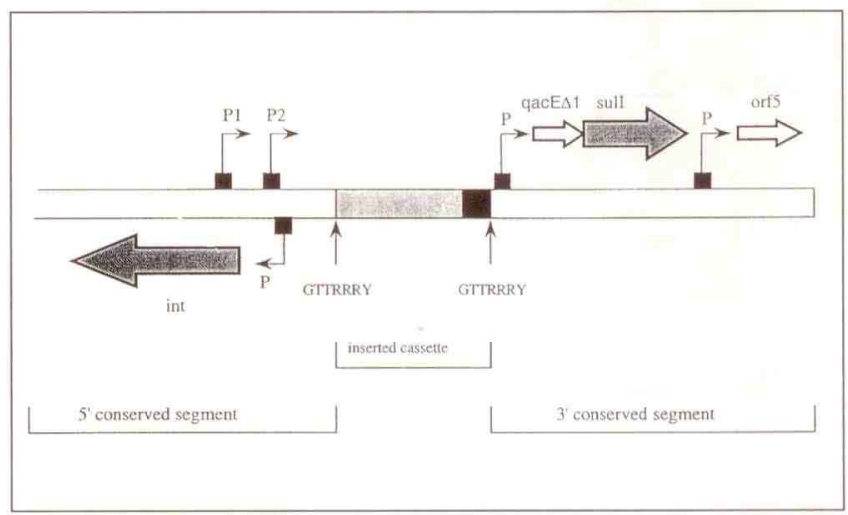

Figure 2) Structure of an integron. A variable central region carries one or more cassettes, each with a palindromic '59-base element' at its downstream end. Promoter P1 occurs in versions of different force due to sequence polymorphisms in the -35 and -10 boxes. In some integrons, an insertion of three guanine residues changes the spacing between another -35 and -10 box from 14 to 17 nucleotides, creating another strong promoter, $P 2$. Site-specific recombination, mediated by the int gene, takes place between $G$ and TT in the GTTRRRY 'core sites'. orf5 open reading frame; qacE $\Delta 1$ Ethidium bromide resistance; sul 1 sulphonamide resistance

mechanism is the aacC3 gene, a common aminoglycoside acetyltransferase encoding gentamicin, tobramycin and netilmicin resistance. This gene can be found both in an 'original' context without insertion sequences and in a context where it is flanked by $I S 140$ s, forming a potential transposon. In the latter arrangement, one of the IS140s furnishes a "-35 sequence', thereby increasing the transcriptional expression of the resistance gene (21).

\section{INTEGRONS}

Integrons (Figure 2) were discovered in the mid-1980s, after restriction maps and electron microscopy of heteroduplexes revealed similarities in many resistance plasmids of Gram-negative bacteria, including those carrying transposons such as Tn21 and its relatives (22). These elements differed often only by an insertion of DNA of the length of one gene. Sequencing revealed that several resistance genes (coding for beta-lactamases, aminoglycoside-modifying enzymes, trimethoprim-resistant dihydrofolate reductases and chloramphenicol resistance) were present as mobile genetic cassettes, each with a short palindromic sequence at the downstream end of the gene, inserted singly or in tandem between two conserved flanking sequences (23-26) (Figure 3). One of these conserved regions codes for an integrase (27), a member of the phage integrase family, now called tyrosine recombinases (28). Cassette integration and excision is done by a mechanism of site-specific recombination mediated by the integrase. It is probable that the integrase and adjacent 'attach site', where the cassettes are integrated, evolved from the int-att region of an ancient bacteriophage.

Integrons have interesting parallels to the expression vectors used in genetic engineering in the laboratory. Expression vectors have a strong promoter, for example the tac promoter (a hybrid between the natural trp and lac promoters) upstream 


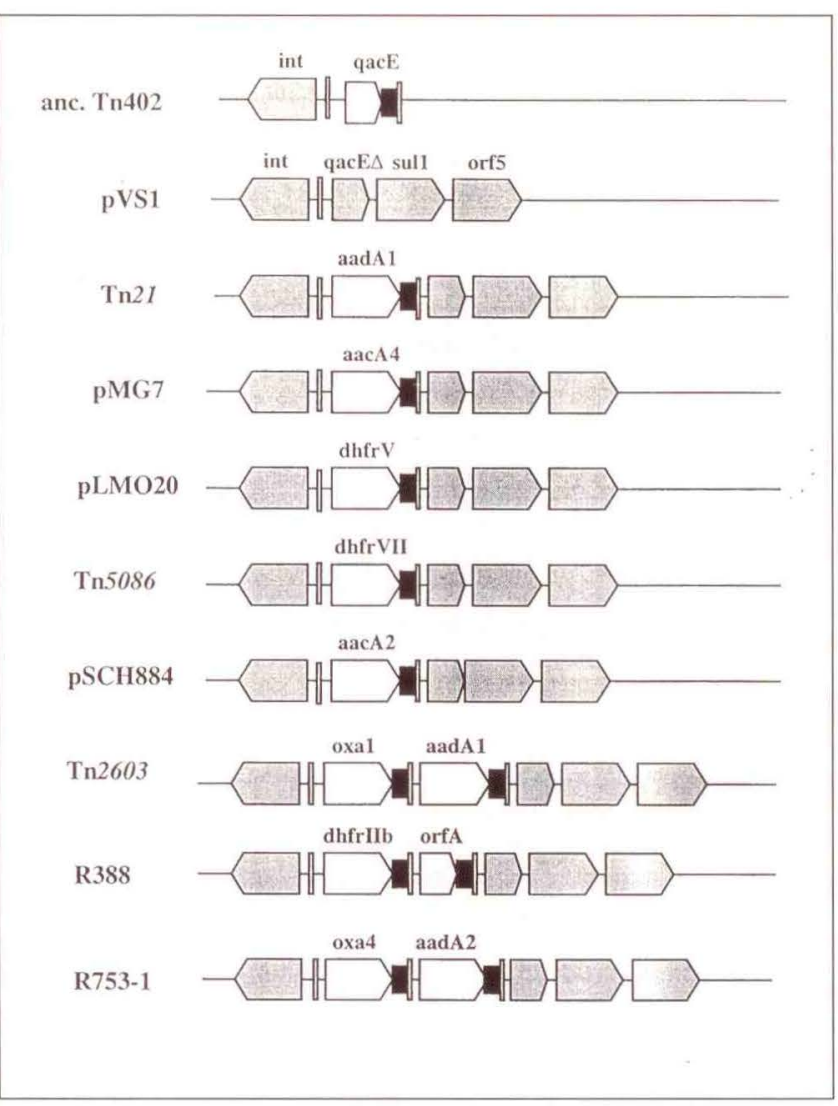

of the site where the target gene is to be cloned. Various integrons have slightly different promoters for expression of the integrated resistance genes. Some versions of these promoters are stronger than the tac promoter (29). Expression vectors have a multiple cloning site downstream of the promoter, where a restriction fragment containing the gene to be cloned can be ligated into place. Integrons use the site-specific recombinational mechanism to integrate cassettes at the attach site, a short distance downstream of the promoter. The integrase recognizes two types of site - the nonpalindromic attach site, and the palindromic '59-base element' found at the end of each cassette. Excision favours a reaction between two palindromic sites (ie, of a cassette in second, third, etc, place), while integration favours a reaction between a nonpalindromic site and a palindromic site (30). The net result is to place (in a small part of the population) a given cassette 'up front' in first position where it is most strongly expressed, and selection does the rest. What remains a mystery is how, and where, resistance structural genes first become associated with 59-base elements to form cassettes. We do know, however, from resistance gene attributes such as guaninecytosine+ content and codon usage that they have a wide variety of origins.

In addition to the cassette mobility in integrons, the integron itself seems to be part of a mobile element, as inferred from its occurrence on plasmids of several incompatibility groups as well as on chromosomes. One integron is part of Tn5090 (also called Tn402), which has a complete set of the four genes required for transposition (31). Most integrons are on defective transposons, missing two of the required genes.

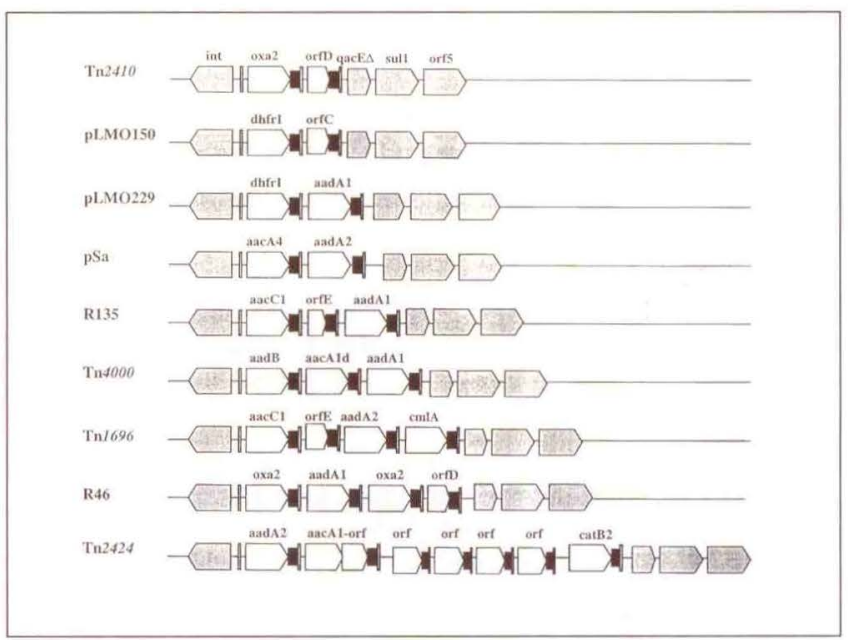

Figure 3) Top and left. Some representative integrons. Genes in the 5, (itit) and ' $3^{\prime}$ (qacE $\Delta$, sul1, and orf5) conserved segments are represented in gray. The GTTRRRY core sites are represented by vertical bars and 59-base elements, which terminate in core sites, as black rectangles. The first line (anc. Tn402) represents a hypothetical ancestor of $\mathrm{Tn} 402$, in which the qacE cassette is complete. In all other integrons shown, qacE is truncated, two of the four transposition genes lost, and sull and orf5 nonspecifically inserted. Transposition genes are not shown because their distance from orf5 varies among the elements. aac Aminoglycoside acetyltransferase; aad Aminoglycoside adenylyltransferase; cat Chloramphenicol acetyltransferase; dhfr Trimethoprimresistant dihydrofolate reductase; orf open reading frame; oxa Oxatype beta-lactamase

However, several integrons 'piggyback' on mercury resistance transposons of the Tn21 family (32). Two additional classes of integrons have been found, although they have a much lesser variety of cassettes. Tn 7 carries an integron, containing cassettes coding for trimethoprim, streptothricin and streptomycin resistance. Only a few relatives of $\operatorname{Tn} 7$, differing in cassette content, are known. The reason for this seems to be that the integrase, which is $50 \%$ identical to that of the principal class of integrons, contains a nonsense mutation (stop codon) in the middle of the gene. Mutagenesis of this codon to a glutamate codon restores activity (personal communication). A third class of integron, first seen in Serratia marcescens, contains a cassette coding for a class beta-lactamase, conferring imipenem resistance (33). Unfortunately, this integron has spread to Klebsiella and Pseudomonas species, and has now spread outside Japan.

A clue to the source of the palindromic 59-base elements can be found in Vibrio choerae, where about $2 \%$ of the genome is made up of structural genes interspersed with $V$ cholerae repeats (VCRs), palindromic elements generally longer and more uniform than 59-base elements (34). Many of the cassettes encode uncharacterized open reading frames, but some appear to encode virulence factors and resistance genes. The ends of the cassette array have now been found, and one flanking sequence codes for an integrase with $50 \%$ amino acid identity to integron integrase (35). It has been shown, at least for cassettes flanked by two palindromic elements, that partial reciprocity for excision exists between 59-base elements and VCRs, and between integron and $V$ cholerae integrases. One 
important difference is that VCRs each contain a promoter for the following gene, thus, the cassette array is much longer. Integron integrase and 59-base elements are undoubtedly of chromosomal or phage origin, and the search for their source is the subject of present intensive investigation.

ACKNOWLEDGEMENTS: This work was supported by grant MT13564 from the Medical Research Council of Canada.

\section{REFERENCES}

1. Davies J. Inactivation of antibiotics and the dissemination of resistance genes. Science 1994;264:375-82.

2. Cohen ML. Epidemiology of drug resistance: implications for a post-antimicrobial era. Science 1992;257:1050-5.

3. Neu HC. The crisis in antibiotic resistance. Science 1992;257:1064-73.

4. Bush K, Jacoby GA, Medeiros AA. A functional classification scheme for beta-lactamases and its correlation with molecular structure. Antimicrob Agents Chemother 1995;39:1211-33.

5. Shaw KJ, Rather PN, Hare RS, Miller GH. Molecular genetics of aminoglycoside resistance genes and familial relationships of the aminoglycoside-modifying enzymes. Microbiol Rev 1993;57:138-63.

6. Rather PN, Munayyer H, Mann PA, Hare RS, Miller GH, Shaw KJ. Genetic analysis of bacterial acetyltransferases: identification of amino acids determining the specificities of the aminoglycoside $6^{\prime}-\mathrm{N}$-acetyltransferase Ib and IIa proteins. J Bacteriol 1992;174:3196-203.

7. Tennigkeit J, Matzura H. Nucleotide sequence analysis of a chloramphenicol-resistance determinant from Agrobacter tumefaciens and identification of its gene product. Gene 1991;98:113-6.

8. Parent R, Roy PH. The chloramphenicol acetyltransferase gene of Tn2424: a new breed of cat. J Bacteriol 1992;174:2891-7.

9. Murray LA, Shaw WV. O-Acetyltransferases for chloramphenicol and other natural products. Antimicrob Agents Chemother 1997;41:1-6.

10. Allignet J, Loncle V, Simenel C, Delepierre M, el Solh N. Sequence of a staphylococcal gene, vat, encoding an acetyltransferase inactivating the A-type compounds of virginiamycin-like antibiotics. Gene 1993;130:91-8.

11. Rende-Fournier R, Leclercq R, Galimand M, Duval J, Courvalin P. Identification of the satA gene encoding a streptogramin A acetyltransferase in Enterococcus faecium BM4145. Antimicrob Agents Chemother 1993;37:2119-25.

12. Spratt BG. Resistance to antibiotics mediated by target alterations. Science 1994;264:388-93.

13. Dowson CG, Coffey TJ, Spratt BG. Origin and molecular epidemiology of penicillin-binding-protein-mediated resistance to B-lactam antibiotics. Trends Microbiol 1994;2:361-6.

14. Huovinen P, Sundström L, Swedberg G, Sköld O. Trimethoprim and sulfonamide resistance. Antimicrob Agents Chemother 1995;39:279-89.

15. Nikaido H. Prevention of drug access to bacterial targets: permeability barriers and active efflux. Science 1994;264:382-8.

16. Poole K. Bacterial multidrug resistance - emphasis on efflux mechanisms and Pseudomonas aeruginosa. J Antimicrob Chemother 1994;34:453-6.

17. Pao SS, Paulsen IT, Saier NM Jr. Major facilitator superfamily. Microbiol Mol Biol Rev 1998;62:1-34.

18. McNicol PJ, Albritton WL, Ronald AR. Characterization of ampicillin resistance plasmids of Haemophilus ducreyi and
Neisseria gonorrhoeae with regard to location of origin of transfer and mobilization by a conjugative plasmid of Haemophilus ducreyi. J Bacteriol 1983;156:437-40.

19. Arthur M, Molinas C, Courvalin P. The VanS-VanR two-component regulatory system controls synthesis of depsipeptide peptidoglycan precursors in Enterococcus faecium BM4147. J Bacteriol 1992;174:2582-91.

20. Marshall CG, Lessard IA, Park I, Wright GD. Glycopeptide antibiotic resistance genes in glycopeptide-producing organisms. Antimicrob Agents Chemother 1998;42:2215-20.

21. Allmansberger R, Brau B, Piepersberg W. Genes for gentamicin-(3)-N-acetyl-transferases III and IV. II. Nucleotide sequences of three $\mathrm{AAC}(3)$-III genes and evolutionary aspects. Mol Gen Genet 1985;198:514-20.

22. Stokes HW, Hall RM. A novel family of potentially mobile DNA elements encoding site-specific gene-integration functions: integrons. Mol Microbiol 1989;3:1669-83.

23. Cameron FH, Groot Obbink DJ, Ackerman VP, Hall RM. Nucleotide sequence of the $\operatorname{AAD}\left(2^{\prime \prime}\right)$ aminoglycoside adenylyltransferase determinant $a a d B$. Evolutionary relationship of this region with those surrounding aadA in R538-1 and dhfrII in R388. Nucleic Acids Res 1986; 14:8625-35.

24. Hall RM, Vockler C. The region of the IncN plasmid R46 coding for resistance to B-lactam antibiotics, streptomycin/ spectinomycin and sulphonamides is closely related to antibiotic resistance segments found in IncW plasmids and in Tn21-like transposons. Nucleic Acids Res 1987;15:7491-501.

25. Ouellette M, Bissonnette L, Roy PH. Precise insertion of antibiotic resistance determinants into Tn21-like transposons: nucleotide sequence of the OXA-1 B-lactamase gene. Proc Natl Acad Sci USA 1987;84:7378-82.

26. Sundström L, Rådström P, Swedberg G, Sköld O. Site-specific recombination promotes linkage between trimethoprim and sulfonamide resistance genes. Sequence characterization of dhfiv and sull and a recombination active locus in $\mathrm{Tn} 21$. Mol Gen Genet 1988;213:191-201.

27. Ouellette M, Roy PH. Homology of ORFs from Tn2603 and from R46 to site-specific recombinases. Nucleic Acids Res 1987; 15:10055.

28. Esposito D, Scocca JJ. The integrase family of tyrosine recombinases: evolution of a conserved active site domain. Nucleic Acids Res 1997;25:3605-14.

29. Lévesque C, Brassard S, Lapointe J, Roy PH. Diversity and relative strength of tandem promoters for the antibiotic-resistance genes of several integrons. Gene 1994;142:49-54.

30. Collis CM, Grammaticopoulos G, Briton J, Stokes HW, Hall RM. Site-specific insertion of gene cassettes into integrons. Mol Microbiol 1993;9:41-52.

31. Rådström P, Sköld O, Swedberg G, Flensburg J, Roy PH, Sundström L. Transposon Tn5090 of plasmid R751, which carries an integron, is related to $\operatorname{Tn} 7, \mathrm{Mu}$, and the retroelements. J Bacteriol 1994;176:3257-68.

32. Liebert CA, Watson AL, Summers AO. Transposon Tn21: flagship of the floating genome. Genbank file AFO71413. Microbiol Mol Biol Rev. (In press)

33. Arakawa Y, Murakami M, Suzuki K, et al. A novel integron-like element carrying the metallo-beta-lactamase gene blaIMP. Antimicrob Agents Chemother 1995;39:1612-5.

34. Barker A, Clark CA, Manning PA. Identification of VCR, a repeated sequence associated with a locus encoding a hemagglutinin in Vibrio cholerae 01. J Bacteriol 1994;176:5450-8.

35. Mazel D, Dychinco B, Webb VA, Davies J. A distinctive class of integron in the Vibrio cholerae genome. Science 1998;280:605-8. 


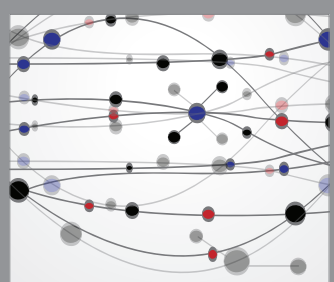

The Scientific World Journal
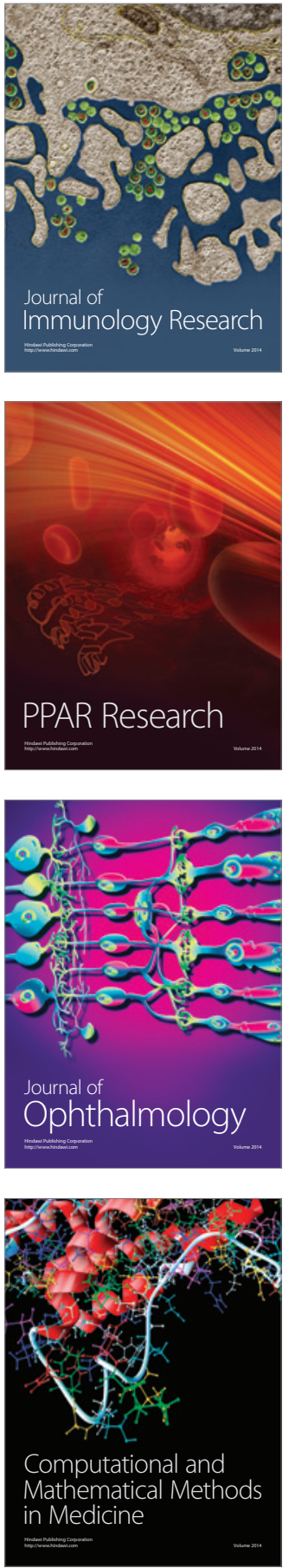

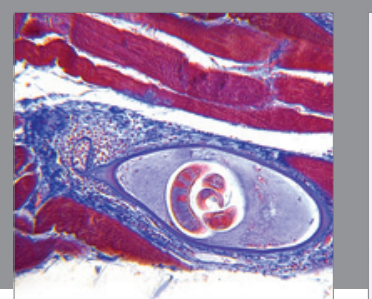

Gastroenterology Research and Practice

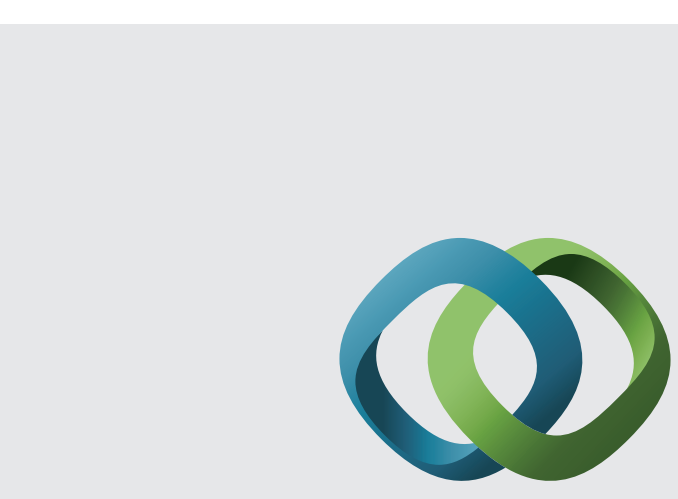

\section{Hindawi}

Submit your manuscripts at

http://www.hindawi.com
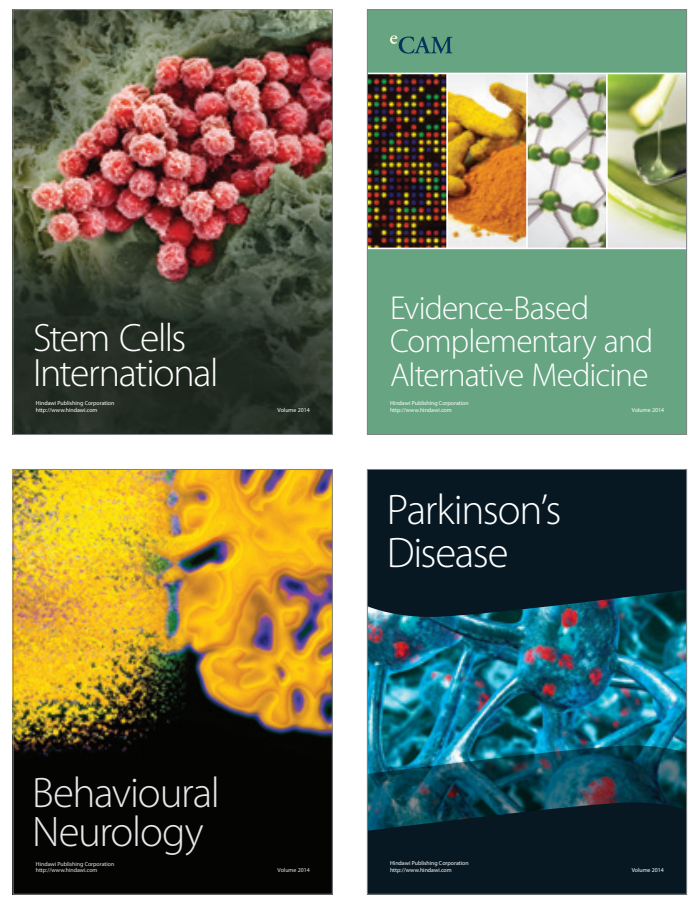
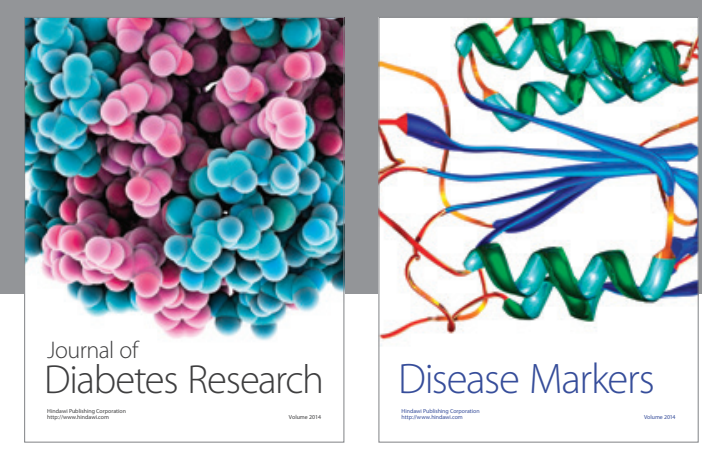

Disease Markers
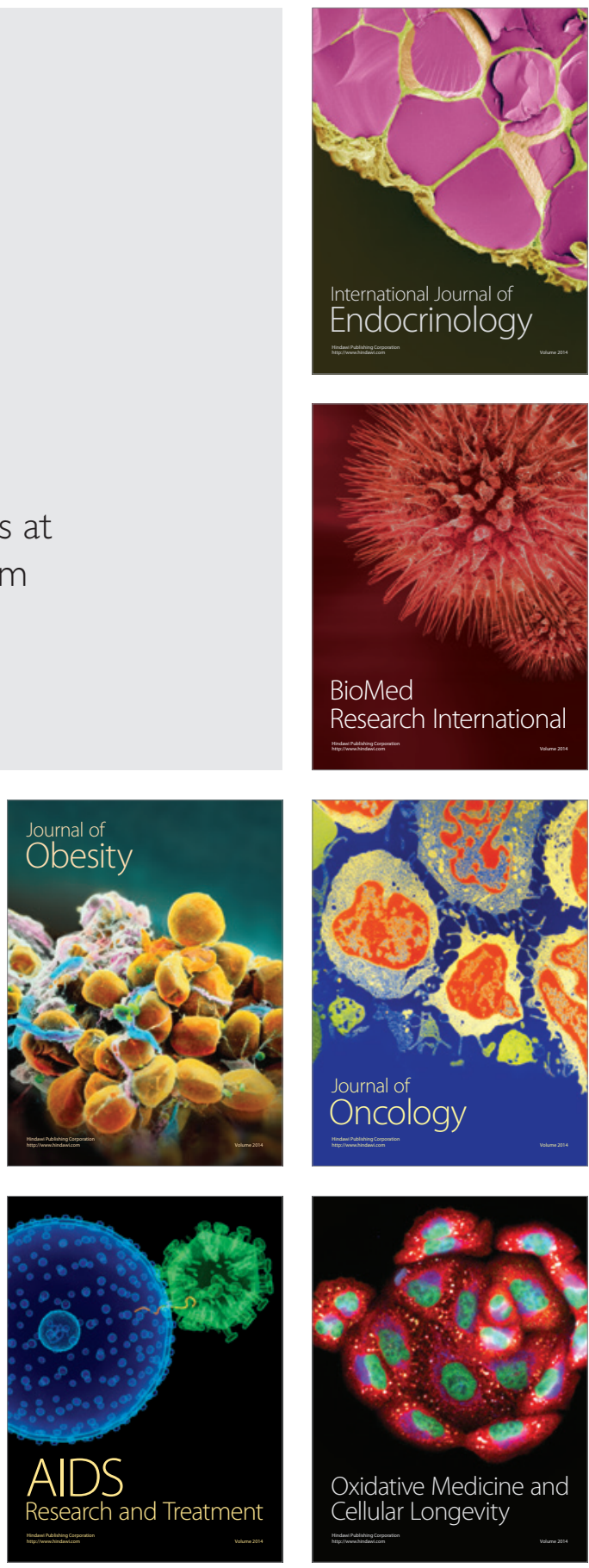